\title{
COVID-19 Sample Collection Kiosk in AIIMS Rishikesh: A safe and efficient model
}

\author{
Sheen Job ${ }^{1}$, Yogesh Bahurupi ${ }^{2}$, Puneet Kumar Gupta ${ }^{3}$, Mahendra Singh ${ }^{4}$, Prasan Kumar Panda ${ }^{5}$, \\ Pradeep Aggarwal ${ }^{6}$, Udai Bhasker Mishra ${ }^{7}$
}

${ }^{1} \mathrm{MPH}$ Student, Department of Community and Family Medicine, All India Institute of Medical Sciences (AlIMS) Rishikesh, Uttarakhand -249203; ${ }^{2}$ Assistant Professor, Department of Community and Family Medicine, All India Institute of Medical Sciences (AlIMS) Rishikesh, Uttarakhand -249203; ${ }^{3}$ Associate Professor, Department of Microbiology, All India Institute of Medical Sciences (AIIMS) Bilaspur, Himachal Pradesh; ${ }^{4}$ Assistant Professor, Department of Community and Family Medicine, All India Institute of Medical Sciences (AlIMS), Rishikesh, Uttarakhand -249203; ${ }^{5}$ Assistant Professor, Department of General Medicine, All India Institute of Medical Sciences (AlIMS), Rishikesh, Uttarakhand -249203; ${ }^{6}$ Associate Professor, Department of Community \& Family Medicine, All India Institute of Medical Sciences (AlIMS), Rishikesh, Uttarakhand -249203; ${ }^{7}$ Dean Hospital Affairs, All India Institute of Medical Sciences (AlIMS), Rishikesh, Uttarakhand -249203

\begin{tabular}{|c|c|c|c|c|c|c|c|c|}
\hline Abstract & Introduction & Methodology & Results & Conclusion & References & Citation & \multicolumn{2}{|c|}{ Tables / Figures } \\
\hline \multicolumn{9}{|c|}{ Corresponding Author } \\
\hline \multicolumn{8}{|c|}{$\begin{array}{l}\text { Dr Yogesh Bahurupi, Assistant Professor, Department of Community and Family medicine, All India } \\
\text { Institute of Medical Sciences (AIIMS) Rishikesh, Uttarakhand -249203 } \\
\text { E Mail ID: } \underline{\text { dr.yogeshab@gmail.com }}\end{array}$} & 口回语回 \\
\hline
\end{tabular}

\section{Citation}

Job S, Bahurupi Y, Gupta PK, Singh M, Panda PK, Aggarwal P, Mishra UB. COVID-19 Sample Collection Kiosk in AllMS Rishikesh: A safe and efficient model. Indian J Comm Health. 2021;33(1):03-08. https://doi.org/10.47203/IJCH.2021.v33i01.002

Source of Funding: Nil Conflict of Interest: None declared

\section{Article Cycle}

Received: 15/01/2021; Revision: 24/02/2021; Accepted: 05/03/2021; Published: 31/03/2021

This work is licensed under a Creative Commons Attribution 4.0 International License.

\section{Abstract}

Introduction: Following the pandemic, screening suspected individuals on a large scale is imperative to curtail the spread of the disease to a large extent. The walk-in kiosk is an ideal example of an innovation that is time and labour efficient and safe to use. Methodology and review of literature: Embase, Google Scholar, and PubMed were used to extract scholarly articles about the subject published worldwide. The Walk-in kiosk concept was an idea taken from the biosafety chamber used in advanced microbiology laboratories. Results: This ergonomic design enabled the HCW to perform better without bending forward or reaching out for the oropharyngeal or nasopharyngeal swabs. It avoids a great deal of inconvenience for both HCW and the patient.

\section{Keywords}

COVID-19; RTPCR; Sample Collection Kiosk; Health care workers; Innovation

\section{Introduction}

The world is now in the grip of a pandemic with over 10 million COVID-19 positive cases, five lakh deaths, and counting. Three months after the outbreak reached epidemic proportions and crossed the regional boundaries, the World Health Organization declared COVID-19 a pandemic.(1) Much time for preparedness had elapsed to control the pandemic.
Following this, the Government of India (Gol) declared measures to contain the disease by an efficient screening of suspected cases all over the country. The Ministry of Health and Family Welfare (MOHFW) directed all state governments to initiate action in line with the policy. With the country in lockdown for over 87 days, COVID-19 cases are rapidly increasing. Globally, in the same way, the 

protection of healthcare workers (HCWs) is a cause of concern when dealing with COVID-19 patients. It is a well-known fact that during nasopharyngeal/throat sample collection, HCWs are heavily exposed to the virus.

Within a week of the pandemic declaration, South Korea developed walk-in kiosks to collect samples without human intervention, followed by WISK (walk-in sample kiosk) sample kiosks.(2) The "Defence Research and Development Laboratory (DRDL)" in Hyderabad has come up with "COVID-19 Sample Collection Kiosk (COVSACK)". In this case, the suspected COVID-19 cases have to the walk-in kiosk, which has a glass shielding screen and two swabs, oropharyngeal and nasopharyngeal swabs, are taken by HCW through the fixed gloves. The built-in cabin's glass shield screen protects them from aerosols and transmission due to the procedure. It reduces the requirement for costly personal protection equipment (PPE) that must be changed by HCW after each sample collection.(3)

\section{Aims \& Objectives}

This review article will introduce various sampling kiosk design used for sample collection and then describe the walk in kiosk at AIIMS Rishikesh.

\section{Material \& Methods}

Databases, namely Embase, Google Scholar, and PubMed, were used to extract scholarly articles about the subject published worldwide. However, the diversity of publications from various researchers worldwide is a fruitful insight. The Walkin kiosk concept is new, and innovation was an idea taken from the biosafety chamber used in advanced microbiology laboratories.

Innovative kiosks

There are models of Kiosks designed for COVID-19 sampling. These are drive-through kiosks, walk-in kiosks, and mobile kiosks. All of them served the same purpose of facilitating sample collection of nasal and oropharyngeal swabs from suspected patients. However, this design has distinct advantages and disadvantages.

\section{A. Drive-through kiosks(4)}

A drive-through (DT) screening centre has its pros and cons; most noteworthy is location, which has to be remotely located outside the city limits with a large population. The space for parking a large number of vehicles is a concern, and even if it is a smaller area, a reservation system has to be planned to avoid chaos in the DT centre. Careful monitoring of patient flow in their vehicles is essential to avoid congestion, and guidance for the procedure to be followed at every step should be provided. The HCWs require a camping site in the facility; hence, a building or an open tent is designated for the examiners. The HCWs will have to stay in these arrangements for a more extended period. The outdoor tent facility is not free of risk, although it is well ventilated.

On the contrary, the assigned building also needs to be re-appropriated for living and basic comfort. The process is simple, the window is kept open a few inches on the patient side, and the HCW takes the swab sample, both oral and nasopharyngeal. The air conditioning and ventilation of the vehicle were kept in internal mode to prevent contamination. To further reduce the risk of exposure, both for the $\mathrm{HCW}$ and the patients, an additional disposable apron is worn over the PPE to avoid crosscontamination, as the PPE may be stained with viral droplets. New gloves were worn and discarded after every test by the HCW. Rigorous hand hygiene is practiced using an alcohol-based steriliser.

The facility provides instructions on how the tests are carried out; they are advised home quarantine until the reports are available and report to the nearest healthcare units if symptoms deteriorate.

\section{B. Walk-in kiosk(1)}

These centres were established in hospitals, airports, railway stations, and designated areas, as decided by the administration. This requires less space and human resources. It is a glass-shielded container booth that can house one HCW trained to perform the test and is closed while the person is inside. It is airconditioned with a ventilation system, which ensures airflow from the outside to the inside. This negative pressure is needed to maintain the airflow from the outside to the inside, and not in the opposite direction. The HCWs are shielded from the COVID-19 suspect by the long glass shield and have two exit holes that can manoeuvre the examiner's arms as desired. The patient was positioned with a tilted head to expose the nasal passages to take the swab and oropharyngeal cavity.

AlIMS Rishikesh, which established the kiosk at the end of April 2020, collected samples for COVID-19 suspects. Every HCW needed to change the PPE before testing the next client. This was an overburden of the country's limited economic resources, and much of the safety could have been compromised. With the advent of the walk-in kiosk, 
these differences cease to exist, and more testing per day is possible with limited resources, saving finances, and ensuring the safety of the HCW. The cost of establishing a Kiosk is economical and can be functional at various points for a more extended period.

However, the disadvantages exist which needs due consideration:

1. Frequent movement in and out of the kiosk cubicle may disrupt the air pressure, causing a reversal of airflow, which puts the HCW at risk.

2. Knowing the virus's viability on various surfaces, fomite exposure, etc., the booth's exposed surface, which may be stained with aerosol after a screening, is mandatorily disinfected as per infection prevention control protocol.

3. In the event of power outages or dysfunctional air-conditioning, a backup measure to prevent air backflow should be installed to avoid crosscontamination.(5)

\section{Mobile kiosks}

It is a smaller version of the walk-in kiosk, which can be mounted in a vehicle and transported to the locality, a containment zone for further screening in large numbers. However, swab collection resources are required to be dispatched to laboratories without accidental spilling of contents during transportation. The HCWs will also have the burden of working long hours as a rapid change in the examiners, and PPE may not be practiced.(6)

\section{Sample Collection Kiosk Model at AlIMS Rishikesh}

The tertiary care centre in Rishikesh has designed a positive pressure kiosk with modifications (Figure 1), which has an inward exhaust that draws air into the kiosk and an air-conditioner inside. The glass shield has two exit holes for hands to collect swabs and draw air from the kiosk so that the aerosol that is sprayed by inevitable coughing and sneezing by the patients is not carried into the kiosk, potentially endangering the $\mathrm{HCW}$ at work. The temperature was controlled, and the two-way communication system made it easier to communicate with the COVID-19 suspects lined up for the test. The two holes in the glass shield are approximately $20 \mathrm{~cm}$ in diameter and approximately the same distance from the edge of the metal frame on which the glass shield rests. The Kiosk floor level is approximately 4 inches above the patient's floor, with holes in the kiosk at a level of 48 inches above the ground. While taking a sample, $\mathrm{HCW}$ is in a standing position with their face above the level of holes and the patient's head above the level of the holes. HCW wears a plastic apron, gloves (changed for every patient), mask, and direction of the air from inside to outside. This will further decrease the chances of exposure to HCW if any forceful sneeze or cough happens accidentally at the level of holes (in patients with short height). Hence, the hand level of the HCW taking the sample (standing inside the kiosk) is just below the face of the patient standing outside the kiosk. This ergonomic design enables the HCW to perform better without bending forward or reaching out for the oropharyngeal or nasopharyngeal swab. It avoids a great deal of inconvenience for both HCW and the patient. Another advantage of this standing position of taking samples to prevent cleaning and disinfection of the sitting material is used for patients. However, it may sometimes be inconvenient for patients of extreme height with the requirement to bend.

The kiosk dimension was 4 feet in length, 4 feet in breadth, and 8.5 feet in height. It has an exhaust fitted that draws air into the kiosk where the HCW is seated to collect COVID-19suspects' samples. The exhaust is 9-inch, with a 40-watt fan maintaining approximately 22 air changes per hour inside the Kiosk. There is a door for entry to Kiosk just below the exhaust, and it is kept closed while collecting the sample. All three sides of the Kiosk are made up of plywood with acrylic emulsion paint coated to make it smooth and easy to clean and disinfect. Opposite to the door and exhaust side is a transparent glass side with two exit holes that draw air out of the kiosk so that the aerosol that is sprayed by inevitable coughing and sneezing by the patients is not carried into the kiosk, potentially endangering the $\mathrm{HCW}$ at work. Inside the Kiosk, the temperature was well controlled by the installation of a split air conditioning system. The two-way communication system makes it easier to communicate with COVID19 suspects that are lined up for the test. On one side, just outside the glass, there is self for hand rub, and on the other side, foot-operated biomedical waste bins are kept.

Every suspected COVID-19 patient is pre-labeled with patient details viral transport medium (VTM) from the outpatient COVID-19 screening in polythene sealed pouches. At Kiosk, the patient performed hand hygiene using an alcohol-based hand rub and removed the VTM. HCW describes the procedure for the patient through a two-way 
communication system. HCW, who is inside the Kiosk, collects samples (nasopharyngeal first followed by oropharyngeal swab) through the aperture made in the Kiosk with his gloved hands. After collection, the swabs were placed inside the VTM vial (already opened by the patient as communicated).

After this, the patient closes the vial, cleans the vial's outer surface, and places it back in the pouch. The patient cleans the pouch with a hand-rub solution. The plastic pouch containing a sample inside the VTM was kept by the patient in a vaccine carrier box (with ice packs to maintain a temperature of approximately $40 \mathrm{C}^{\circ} \mathrm{C}$ ). After this, gloves of $\mathrm{HCW}$ are discarded in the biomedical bin and hand hygiene is performed before leaving the area. At the same time, HCW also performs hand hygiene with hands outside the port and is set again for the next patient. This kiosk is in open air, and there is a continuous replacement of air in the patient area. However, for the next patient coming in for sample collection, at least $2 \mathrm{~m}$, the safety distance is maintained between them. Every four-hour outer glass surface of the Kiosk and other exterior areas was cleaned with a hypochlorite solution. The patient's average time at Kiosk was 2-3 min for the sample test.

The walk-in kiosk is a time-saving and labor-saving sampling booth. It is simple in design and convenient to operate in a hospital setting, airport, railway station, or any designated place by the administration. The $\mathrm{HCW}$ requires training to develop skills. The walk-in kiosk is also an economical design; the sample can be taken from the COVID-19 suspects in two min, both oropharyngeal and nasopharyngeal swabs. The kiosk can be operated by a single HCW, which saves PPE as well as limited resources. The HCW can stand inside the kiosk and collect throat swabs without exposing themselves to the person under observation. Each kiosk cost approximately Rs. 40,000. The samples were collected in a controlled environment. The positive pressure system ensures that the air inside the sample kiosk is blown out through the exit holes of the glass shield. This airflow system directs aerosol flow from the airways of the patients outward and not into the kiosk. However, regular sanitisation with disinfectants is required to keep the surfaces in contact sterile. The ease of operation and its convenience, ensuring all safety precautions, are the hallmarks of a walk-in kiosk.

\section{Conclusion}

The walk-in kiosk has been a unique example of saving human resources and resources when there is a severe crunch. It may be considered for use in all institutions and transit centres because of its ease of operation with limited resources. It is a cost-effective way of expediting the daunting task of testing or screening large numbers of COVID-19 suspects in India. The AIIMS Rishikesh model, which has a unique set of positive pressure inside and air conditioning, is safer and more comfortable for HCWs can be used everywhere. In these difficult times, the whole world can only bank on the preventive aspects of transmitting the disease to keep themselves safe and healthy.

\section{Recommendation}

Walk in kiosk is now a more sustainable option than just an experimental model for health care providers for quicker and better screening. During the surge of COVID-19, screening large numbers of the population in a short time was overcome by this great innovation.

The future lies in furthering the usefulness of this concept with the incorporation of artificial intelligence (Al). A set of sensors with a pre-set algorithm for monitoring various temperatures, heart rate parameters, and respiratory rate can be incorporated, and the data collected by the sensors are analysed by the software devices mounted in the chamber. It can also be linked to an app such as Arogya Setu; with the social security ID, the available data is a bioinformatics domain. It may be a concept for now, but it may well be perceived as a state-ofthe-art technology in the future.

\section{Relevance of the study}

The innovative design for COVID-19 sampling is fast and effective, and is a safe and practical method. It needs a glass shield cubicle with airflow and temperature specifications, which protects the healthcare worker from airborne or physical contact while taking the sample. It has proven to be less laborious and less time-consuming and can be adopted at various outdoor locations, as needed for mass screening.

\section{Authors Contribution}

All authors were equally contributed for literature review, data collection and preparation of manuscript. 


\section{Acknowledgement}

With the concept of a walk-in kiosk, the engineering team of AllMS Rishikesh was pivotal in developing the design into a fully operational unit. We acknowledge the Superintending Engineer and his team's efforts to erect the walk-in kiosk and make it fully functional in a timely manner.

\section{References}

1. Kim SI, Lee JY. Walk-Through Screening Center for COVID19: an Accessible and Efficient Screening System in a Pandemic Situation. J Korean Med Sci. 2020;35(15): e154. doi: 10.3346/jkms.2020.35. e154. PMID: 32301300; PMCID: PMC7167399.[PubMed]

2. Lee J. COVID-19 Screening Center: How to Balance between the Speed and Safety? J Korean Med Sci. 2020;35(15):e157. doi: 10.3346/jkms.2020.35.e157. PMID: 32301302; PMCID: PMC7167407.[PubMed].
DRDL Newsletter, dated 14 April 2020, PIB, press information bulletin, https://pib.gov.in/PressReleasePage.aspx?PRID=1614372

4. Kwon KT, Ko JH, Shin H, Sung M, Kim JY. Drive-Through Screening Center for COVID-19: a Safe and Efficient Screening System against Massive Community Outbreak. J Korean Med Sci. 2020;35(11):e123. doi: 10.3346/jkms.2020.35.e123. PMID: 32193904; PMCID: PMC7086085.[PubMed]

5. Kim KM, Han SH, Yoo SY, Yoo JH. Potential Hazards of Concern in the Walk- Through Screening System for the Corona Virus Disease 2019 from the Perspective of Infection Preventionists. J Korean Med Sci. 2020;35(15):e156. doi: 10.3346/jkms.2020.35.e156. PMID: 32301301; PMCID: PMC7167405.[PubMed

6. Ministry of Housing \& Urban Affairs. Agartala Smart City uses mobile kiosk for COVID-19 sample collection. Available from

https://pib.gov.in/PressReleasePage.aspx?PRID=1618971

\section{Tables}

\section{TABLE 1 DETAILS OF VARIOUS DESIGNS OF SAMPLING KIOSKS ARE ILLUSTRATED IN TABLE 1}

\begin{tabular}{|c|c|c|c|c|c|}
\hline $\begin{array}{l}\mathrm{Sr} \\
\text { No }\end{array}$ & Name & Developed by & Type & Features & Advantages \\
\hline \multirow[t]{4}{*}{1} & \multirow[t]{4}{*}{ COVSACK } & \multirow{4}{*}{$\begin{array}{l}\text { DRDO (Defence } \\
\text { Research } \\
\text { Development } \\
\text { Organisation } \\
\text { India) }\end{array}$} & \multirow[t]{4}{*}{ Walk-in } & $\begin{array}{l}\text { Patient sampled to be seated inside the } \\
\text { kiosk }\end{array}$ & PPE resources saved \\
\hline & & & & $\begin{array}{l}\text { The health worker takes a sample from } \\
\text { outside the chamber }\end{array}$ & $\begin{array}{l}\text { Benefits worth the cost } \\
\text { invested }\end{array}$ \\
\hline & & & & Disinfection system inbuilt & \\
\hline & & & & Two-way communication for commands & \\
\hline \multirow[t]{2}{*}{2} & \multirow[t]{2}{*}{ WISK } & \multirow[t]{2}{*}{ Govt of Kerala } & \multirow[t]{2}{*}{ Walk-in } & Health worker seated inside the chamber & \multirow{2}{*}{$\begin{array}{l}\text { Workforce and PPE } \\
\text { resources are saved }\end{array}$} \\
\hline & & & & $\begin{array}{l}\text { Patient to be sampled stands outside } 40-50 \\
\text { samples can be taken per day }\end{array}$ & \\
\hline \multirow[t]{4}{*}{3} & \multirow[t]{4}{*}{$\begin{array}{l}\text { Sampling } \\
\text { booth }\end{array}$} & \multirow[t]{4}{*}{ South Korea } & \multirow[t]{4}{*}{ Walk-in } & $\begin{array}{l}\text { Changing plastic gloves and disinfecting the } \\
\text { booth not more than five to seven minutes } \\
\text { per person so that a large number of } \\
\text { samples can be collected in a day }\end{array}$ & \multirow{4}{*}{$\begin{array}{l}\text { The next person } \\
\text { visiting the booth is not } \\
\text { prone to be infected by } \\
\text { the nasal or oral } \\
\text { plumes of the previous } \\
\text { person }\end{array}$} \\
\hline & & & & $\begin{array}{l}\text { The booths built on the Negative pressure } \\
\text { room (NPR) concept of negative pressure in } \\
\text { the chamber }\end{array}$ & \\
\hline & & & & $\begin{array}{l}\text { The air inside the room does not leak out } \\
\text { through the gaps }\end{array}$ & \\
\hline & & & & $\begin{array}{l}\text { Air from inside the booth is discharged } \\
\text { outside in a controlled manner after filtering }\end{array}$ & \\
\hline \multirow[t]{2}{*}{4} & \multirow[t]{2}{*}{$\begin{array}{l}\text { Drive-in } \\
\text { Kiosk }\end{array}$} & \multirow[t]{2}{*}{ South Korea } & \multirow[t]{2}{*}{$\begin{array}{l}\text { Drive- } \\
\text { in Kiosk }\end{array}$} & \multirow{2}{*}{$\begin{array}{l}\text { It takes } 30 \text { minutes for the procedure from } \\
\text { checking to checkout. Beneficiaries need not } \\
\text { step out of the car into the facility }\end{array}$} & $\begin{array}{l}\text { Safe for healthcare } \\
\text { workers }\end{array}$ \\
\hline & & & & & $\begin{array}{l}\text { No PPE kits to be } \\
\text { donned by HCWs for } \\
\text { every test }\end{array}$ \\
\hline \multirow[t]{3}{*}{5} & \multirow[t]{3}{*}{$\begin{array}{l}\text { Mobile } \\
\text { Kiosk }\end{array}$} & \multirow[t]{3}{*}{ Tripura } & \multirow[t]{3}{*}{$\begin{array}{l}\text { Mobile } \\
\text { Kiosk }\end{array}$} & $\begin{array}{l}\text { It can be mounted in a three-wheeler } \\
\text { carriage }\end{array}$ & $\begin{array}{l}\text { Can be sent to any } \\
\text { locality }\end{array}$ \\
\hline & & & & $\begin{array}{l}\text { Fiber body with glass panel and sampling } \\
\text { vents }\end{array}$ & $\begin{array}{l}\text { Effective for screening } \\
\text { in social outreach areas }\end{array}$ \\
\hline & & & & & $\begin{array}{l}\text { The patient need not } \\
\text { travel to the hospital or } \\
\text { diagnostic centre }\end{array}$ \\
\hline
\end{tabular}




\section{Figures}

FIGURE 1 WALK IN KIOSK STATIONED FOR USE

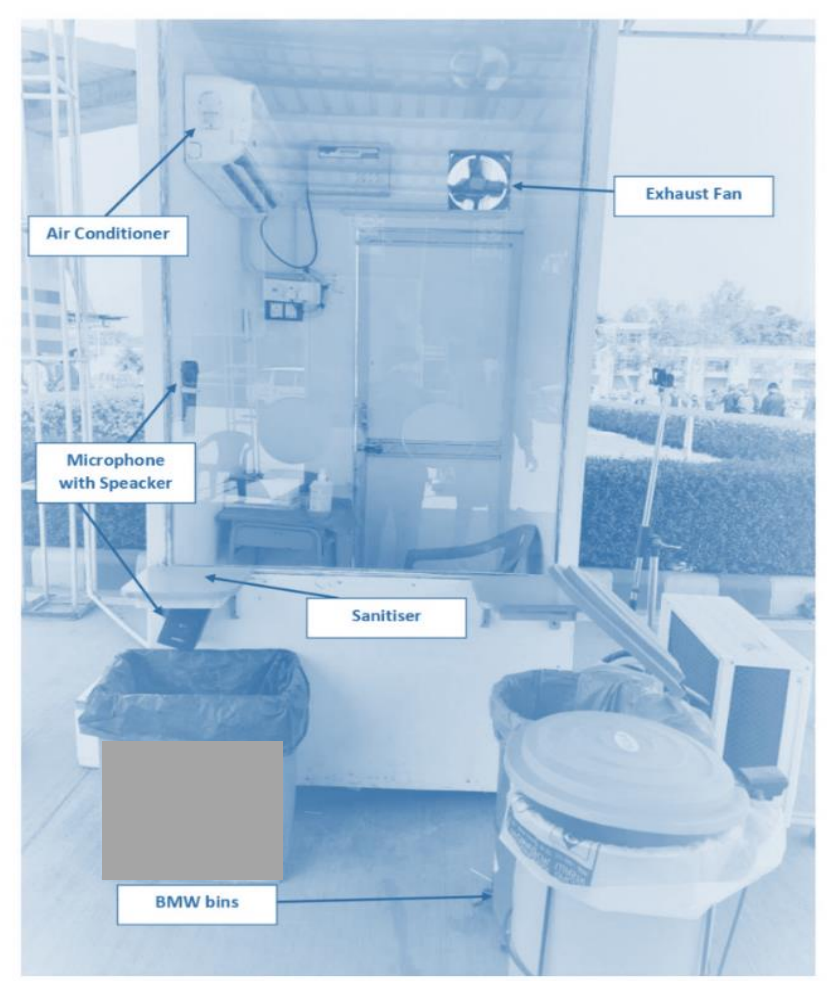

FIGURE 2 SCHEMATIC DIAGRAM OF THE SCREENING CENTRE WITH THE WALK-IN KIOSK
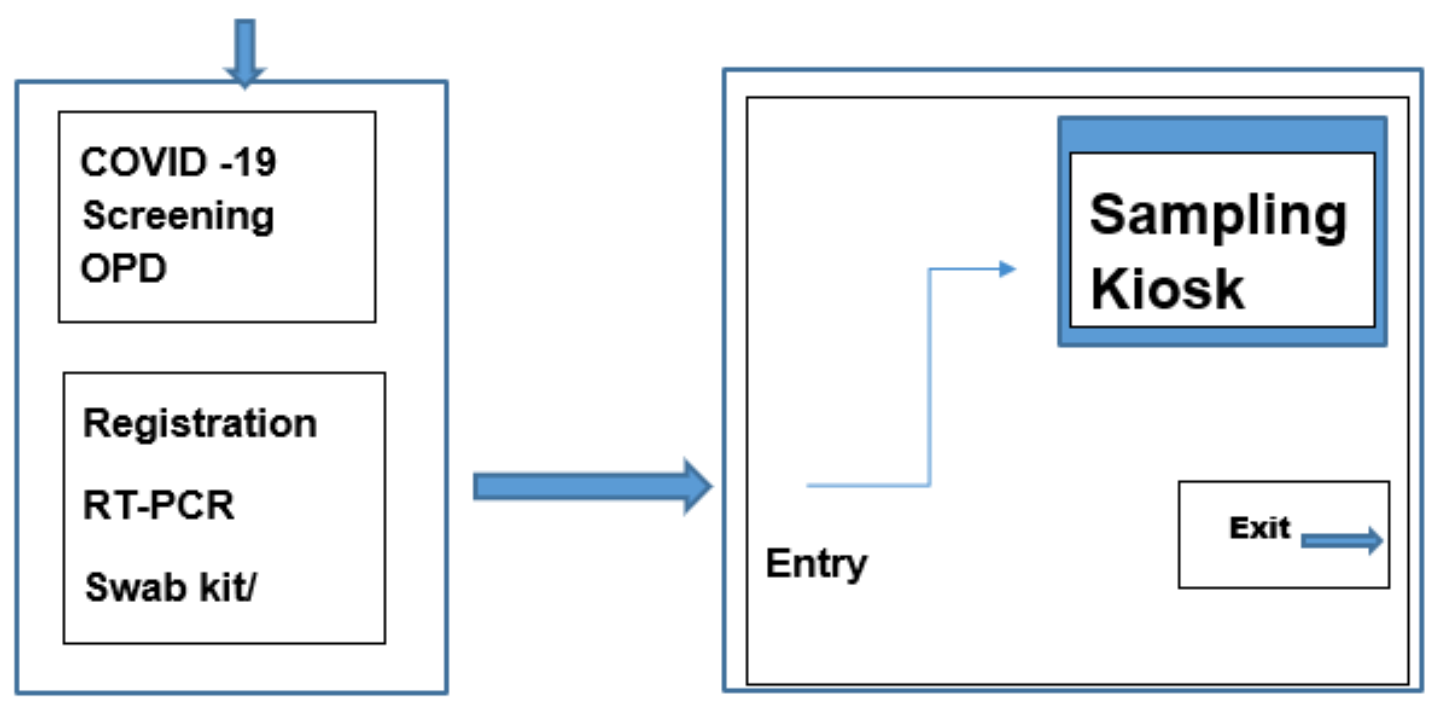